\title{
Comparative Reviews vs. Regular Consumer Reviews:
}

\section{Effects of Presentation Format and Review Valence}

\author{
Hessam Vali, Techam Solutions, USA \\ Jingjun (David) Xu, City University of Hong Kong, Hong Kong \\ Mehmet Bayram Yildirim, Wichita State University, USA
}

\begin{abstract}
This study proposes and evaluates the effect of "mixed" comparative reviews on review value and compares the results with "separate" comparative and regular reviews. A total of 201 subjects have participated in the experiment conducted in this study. Results indicate that mixed comparative reviews in text format are perceived as less valuable than separate comparative reviews in text format. However, mixed comparative reviews in tabular format have more review value than those in text format and are perceived as more valuable than regular reviews of one product in either format. Unsurprisingly, the positive reviews of the target product lead to higher product attitude than negative reviews. However, this effect is weak in mixed (vs. separate) comparative reviews.
\end{abstract}

\section{KEYWORDS}

Consumer Review, Mixed Comparative Review, Presentation Format, Product Attitude, Regular Review, Review Type, Review Valence, Review Value, Separate Comparative Review

\section{INTRODUCTION}

Online consumer reviews have been accepted as one of the primary sources of product information (Chen et al. 2016) and commonly used by global online shoppers (Yin et al. 2016). Global online marketplaces, such as Alibaba and Amazon, provide ways for consumers to write online reviews about their product usage experience. Regular online reviews written by consumers commonly provide information on single products and are referred to as regular reviews in this study. In a competitive market where alternative products are introduced to satisfy customer requirements, potential buyers typically research for alternative products and select the one that provides the maximum value for the allocated budget. As such, multiple reviews are read (Park et al. 2007). However, differences among user preferences and associated shared information may confuse potential buyers and lead to inappropriate purchases (Vali et al. 2015). For example, consider that a professional photographer rates camera A with above-average features as weak, whereas an amateur photographer rates camera B with few features as strong. Due to inconsistent consumer preferences, a buyer may make an incorrect purchase by selecting camera $\mathrm{B}$ with a strong rating but few features.

To address the issues of reviews written by different consumers, we propose a new type of online review, the mixed comparative review, which is a single review written by one consumer to compare two products on the same product attributes. Below are examples of a regular review and a mixed comparative review found on Amazon.com. 
Regular review: "Recreational, uses a phone as a communication device and for fun: iPhone. The camera and social apps are fun to use on the iPhone."

Mixed comparative review: "Photographer, blogger, foodie: iPhone 8 still has the best selection of apps and arguably the best camera. Samsung's camera is slow, and the company is known to really bog down its stellar devices with bloatware that ruins or significantly slows down your phone after one year of use."

Apart from mixed comparative and regular reviews, buyers can access another type of review, that is, two regular reviews written by two different people about two different products (Park et al. 2007). We name this combination as separate comparative reviews. However, different from the mixed comparative reviews written by one consumer, separate comparative reviews written by two consumers with different preferences may result in potential buyer confusion. We include this type of review in our study because in normal circumstances, a buyer likely uses this approach to access consumer reviews about two different products (Park et al. 2007). Marketing literature has proposed comparative advertisements; however, no study has evaluated the effect of this type of comparative message in the online review context.

We compare three types of consumer reviews (mixed comparative, separate comparative, and regular reviews) in terms of review value for three reasons. First, reports on product-return costs, warranty costs, and low-star-rating reviews posted on online marketplaces indicate the need to improve review value (Christozov et al. 2009). As the number of assessed products may increase the overall informativeness of consumer reviews (Decker and Trusov 2010), we examine whether further information provided will translate into increased review value. Second, although the effects of online review properties, such as volume, valence, length, and date of submission, have been investigated in terms of their impact on sellers' sale (Guo and Zhou 2016) and buyers' purchase intention (Park et al. 2007) and decision (Bag et al. 2019), limited studies have focused on how the value of posted reviews can be improved from the perspective of buyers. Sellers are more interested in purchase behavior, whereas consumers are more interested in review value. Our approach is aligned with previous researchers' call to conduct additional consumer-focused research for consumers' welfare, rather than sellers' (Bazerman 2001). Third, review value is a more immediate outcome for different types of reviews than distal outcomes, such as purchase intention and behavior. Evaluating a high review value provided by a website does not necessarily guarantee that a reviewed product will be purchased from the website. Users may merely search for online product information, compare different products online, and/or eventually purchase a different product at a physical store. Users may also consider a review that provides a good review value by summarizing the downsides of the interested products and decide to give up their purchase intention. Thus, rather than examining purchase intention that is related remotely to review type, focusing on review value allows us to observe their direct causal effect.

In addition to investigating the three types of consumer reviews, we study two other moderating factors, namely, review presentation format and review valence. Review presentation format (text vs. tabular) is considered to moderate the relationship between review type and review value. Categorizing and organizing information about a phenomenon can increase the impact of the delivered information (Segel and Heer 2010). However, vast prior research has only considered written reviews as the main presentation format. With the growth of image reviews, some scholars have started looking at other presentation formats, which may affect review helpfulness. Compared with written reviews, imagebased reviews provide higher product understanding (Liu and Du 2019). Inspired by this research, we aim to examine whether presentation format can enhance the effect of mixed comparative reviews.

The other factor, review valence, indicates the theme of an online review and conveys either a generally negative or positive sentiment of the reviewer toward the product or service (Pan et al. 2018). Valence contains product or service descriptions (desirable or undesirable) (Vermeulen and Seegers 2009). A positive review has been argued and accepted to result in high product attitude (Lee et al. 2008). However, its effect also depends on other factors, such as review skepticism, source 
credibility, etc. (Xiao et al. 2019). In this study, we propose that the effect of review valence may depend on the review type (i.e., mixed vs. separate comparative review). Review readers may discount mixed comparative reviews' positive evaluation of the target product and consider it less sincere as the alternative product is attacked (Jain and Posavac 2004).

The study provides the following contributions: First, we propose the mixed comparative review and examine its effects on review value. Thus, this study contributes to existing online consumer review literature and comparative content literature. Second, we examine the moderating role of presentation format in influencing the effect of review type on review value. Accordingly, we contribute to existing visualization literature and cognitive load theory. Finally, we extend attribution theory to the context of comparative consumer reviews by studying the role of review valence in influencing product attitude.

\section{THEORETICAL BACKGROUND}

\section{Mixed Comparative, Separate Comparative, and Regular Consumer Reviews}

Sellers had used advertisements to promote their products long before consumer reviews were introduced. In the 1970s, comparative advertising was introduced and became popular. The increased popularity might be partly due to the Federal Trade Commission's informal encouragement of explicit comparisons (Wilkie and Farris 1975). Comparative reviews have three features. First, such reviews explicitly (e.g., Wilkie and Farris 1975) or implicitly (e.g., Jackson et al. 1979) evaluate at least two brands in the same generic product or service class. Second, comparative reviews evaluate brands on the basis of specific product/service attributes (Wilkie and Farris, 1975). Third, a mixed comparative review may be perceived as a negative comparison as it may include positive information about a sponsored brand and negative information about the competing brand (i.e., "You are bad, but we are good.") (Jain and Posavac 2004; Wu and Wen 2019).

Various studies are then conducted to study the effect of comparative advertising on generating attention, message, and brand awareness; message processing level; favorable sponsored brand attitude; purchase intention and behavior; source believability; attitude toward an advertisement (Grewal et al. .1997). Comparative advertisements are generally found more effective than noncomparative advertisements. However, attitude toward an advertisement is negatively affected when the advertisement is a negative comparative (Jain and Posavac 2004; Wu and Wen 2019). Although extensive literature evaluates the performance of comparative advertisements, to our knowledge, no study has focused on the value of comparative consumer reviews.

\section{Review Value and Product Attitude}

The adoption of review value and product attitude as our dependent variables is based on advertisement literature. Advertising objectives can be classified into two types, namely, cognitive and affective (Lavidge and Steiner 1961). The cognitive function provides information and facts to inform and educate consumers about sponsored brands. This definition implies that high informative content regarding target products increases the value of advertisements. By adopting this function into the consumer review context, valuable online reviews are those that provide highly relevant information about target products and motivate buyers to make appropriate purchase decisions. Customers attempt to understand the justifications of reviewers behind their shared opinions and subsequently assess review value based on their understanding (Singh et al. 2017).

Advertising's affective function induces liking and preference for sponsored brands; preference presumably refers to highly favorable attitude. This function can be evaluated by measuring consumers' attitude toward a product. In the advertisement application, such an attitude denotes consumers' feelings and overall attitude toward the target product. In this study, product attitude is adopted as a dependent variable to analyze the moderating effect of review type (i.e., mixed vs. separate comparative) with review valence as the independent variable. When the product information source 
is a seller advertisement, comparative advertisements generate fewer favorable attitudinal responses toward the product than noncomparative advertisements (Gorn and Weinberg 1984). This context may be due to the perception of the comparison as the sellers' attack to the alternative brand, thereby causing users to derogate from the advertising source of the message (Wu and Wen 2019; Hsu 2018; Jain and Posavac 2004; Gotlieb and Sarel 1991; Wilkie and Farris 1975).

\section{Review Presentation Format}

Using presentation tools to organize content can positively affect the overall information delivered and increase the ease for readers to capture a considerable amount of data with less effort (Segel and Heer 2010). Visualization has long been used to support the delivered information, commonly in the form of diagrams, tables, and charts inserted into a large body of the text. By adopting Segel and Heer's (2010) proposed data visualization into online consumer reviews, visualized information in online reviews is expected to help potential buyers read through online reviews faster and obtain information more effectively than text information. As a result, we propose that categorizing product attributes and corresponding differences in tabular format can help potential buyers capture information more effectively than reading plain text with no visual categorization. Table 1 presents a mixed comparative review in tabular format.

Table 1. Proposed Mixed Comparative Reviews in Tabular Format

\begin{tabular}{|l|l|l|}
\hline \multicolumn{1}{|c|}{ Attribute } & \multicolumn{1}{c|}{ iPhone } & \multicolumn{1}{c|}{ Galaxy } \\
\hline Camera software & $\begin{array}{l}\text { Behind the scenes software for digitally } \\
\text { capturing images is definitely the strongest } \\
\text { sell for the iPhone. This feature was one of } \\
\text { the reasons why I switched over from Galaxy } \\
\text { S6 because I have started to dabble with } \\
\text { photography and wanted a really good camera } \\
\text { in my smartphone. :) }\end{array}$ & $\begin{array}{l}\text { Although the Galaxy S6 camera is amazing, the } \\
\text { overall quality of pictures from the iPhone is } \\
\text { higher. : }:\end{array}$ \\
\hline $\begin{array}{l}\text { Processor } \\
\text { reliability }\end{array}$ & $\begin{array}{l}\text { I believe that the iPhone is more reliable than } \\
\text { the Galaxy. I never experienced any crashes } \\
\text { while using iPhone 6 for two months. :) }\end{array}$ & $\begin{array}{l}\text { I used a Galaxy S6 for the same amount of time } \\
\text { and a similar application, and my cellphone } \\
\text { crashed several times, so I had to restart it. : }:\end{array}$ \\
\hline
\end{tabular}

\section{Similarity and Difference With Extant Literature}

Table 2 provides a summary of the major studies in the literature of online consumer reviews and advertisements and reveals that review value and attitude toward a product are two commonly consequently variables adopted in the online consumer review and advertisement literature to investigate the different types of online consumer reviews and advertisements (D' acunto et al. 2020; Filieri et al. 2019; Chen et al. 2016; Liu et al. 2015; Chen and Lurie 2013; Lee et al. 2008). Table 2 demonstrates that a couple of studies have investigated the effects of comparative advertisements on message value and product attitude. However, only few studies have examined the effects of comparative online reviews and review presentation formats in the context of online consumer reviews. Advertisements are produced by sellers, yet online reviews are generated by consumers. Thus, whether the prior findings in the advertisement literature can directly be applied to the online review context is unclear, which necessitates this current research. This study draws upon the cognitive load in multimedia learning (Mayer and Moreno 2003; Sorden 2012) and visualization research (Segel and Heer 2010) to shed light on the effects of comparative reviews and review presentation formats. 


\section{HYPOTHESIS DEVELOPMENT}

\section{Interaction Effect of Review Type and Presentation Format}

We expect that presentation format (tabular vs. text) can moderate the effects of mixed comparative reviews (vs. regular reviews) on perceived review value. When the reviews are presented in pure text format, we predict no difference between mixed comparative reviews and regular reviews about one product. According to cognitive load and cognitive theory in multimedia learning, people have limited working memory to process incoming information. Thus, if a person's working memory is overloaded, then the learning process is negatively affected (Xu et al. 2013). When mixed comparative reviews are presented in text format, a buyer reads many words and sentences, analyzes the unorganized information, makes connections between text and product attributes, and decides which product is more favorable. This level of information processing may require high working memory and result in a brain overload condition. Meanwhile, regular reviews about one product have less complexity and therefore require less working memory. In sum, although mixed comparative reviews provide additional information about alternative products, the reviews are unorganized and may overload users; thus, mixed comparative reviews have limited added benefits over regular reviews.

When the reviews are presented in tabular format, although mixed reviews still push more information to buyers to process and therefore higher working memory is required, the tabular format of the reviews makes the analysis of product attribute information easier and more effective (Segel and Heer 2010), resulting in being more valuable than regular reviews. The cognitive theory of multimedia learning posits that "multiple-channel communications appear to be superior to singlechannel communications when relevant cues are summated across channels" (Severin 1967, p. 397). That is, effective learning occurs when the number of available cues or stimuli increases (Moore et al. 2004; Severin 1967). In the online review context, visual cues, such as tabular format, may complement text cues to help users understand review contents. In this scenario, mixed comparative reviews provide additional information about alternative products but in an organized manner, which helps buyers capture information more effectively with less short-term memory involved. Therefore, tabular mixed comparative reviews can have more review value than regular reviews. We propose the following hypothesis:

H1a: The effect of review type on review value is moderated by the review presentation format, such that the mixed comparative review of two products is perceived to be more valuable when it is presented in tabular (vs. text) format than a regular review for a single product.

We then examine the moderating role of presentation format between mixed (vs. separate) comparative reviews and review value. When these reviews are presented in text format, the information of separate comparative reviews is already organized by the product because each of its reviews is written separately by a different reviewer about one of the two comparing products. Such categorized information can be analyzed faster than non-categorized information (Segel and Heer 2010) because online shoppers can easily identify the product information that they are interested in and obtain the information more effectively than the mixed comparative review about two alternatives (Appendix 1 Website 1). By contrast, the information in the mixed comparative reviews about a particular product is not easily separated and requires more short-term memory to process and digest the provided reviews. Thus, shoppers perceive mixed comparative reviews to have less review value than separate comparative reviews.

We expect that the positive effect of tabular (vs. text) presentation format will be more prominent for mixed comparative reviews but less salient for separate comparative reviews. On the one hand, simply adding a table surrounding the text content for each review does not lead to much difference for separate comparative reviews in text format. On the other hand, when mixed comparative reviews are presented in tabular format, the review comments about each product and its attributes are well 
Table 2. Selected Consumer Review and Advertisement Literatures

\begin{tabular}{|c|c|c|c|c|c|c|c|}
\hline \multirow[b]{2}{*}{ Literature } & \multirow[b]{2}{*}{ Year } & \multirow[b]{2}{*}{ Context } & \multicolumn{5}{|c|}{ Key constructs studied } \\
\hline & & & $\begin{array}{c}\text { Mixed } \\
\text { comparative } \\
\text { review }\end{array}$ & $\begin{array}{c}\text { Review } \\
\text { presentation } \\
\text { format }\end{array}$ & $\begin{array}{l}\text { Review } \\
\text { valence }\end{array}$ & $\begin{array}{l}\text { Review } \\
\text { value }\end{array}$ & $\begin{array}{c}\text { Attitude } \\
\text { toward a } \\
\text { product }\end{array}$ \\
\hline D'acunto et al. & 2020 & Online reviews & & & & $\mathrm{X}$ & \\
\hline Filieri et. al & 2019 & Online reviews & & & $\mathrm{X}$ & $\mathrm{X}$ & \\
\hline Bag et al. & 2019 & Online reviews & & & & & \\
\hline Pan et al. & 2018 & Online reviews & & & $\mathrm{X}$ & & $\mathrm{X}$ \\
\hline Chen et al. & 2016 & Online reviews & & & & $\mathrm{X}$ & $\mathrm{X}$ \\
\hline Yin et al. & 2016 & Online reviews & & & $\mathrm{X}$ & & \\
\hline Liu et al. & 2015 & Online reviews & & & & & $\mathrm{X}$ \\
\hline Paharia et al. & 2014 & Advertisements & $\mathrm{X}$ & & & & $\mathrm{X}$ \\
\hline Chen and Lurie & 2013 & Online reviews & & & $\mathrm{X}$ & $\mathrm{X}$ & \\
\hline Sorden & 2012 & $\begin{array}{l}\text { Multimedia } \\
\text { learning }\end{array}$ & & $\mathrm{X}$ & & & \\
\hline Korfiatis et al. & 2012 & Online reviews & & & $\mathrm{X}$ & $\mathrm{X}$ & \\
\hline Connors et al. & 2011 & Online reviews & & & & $\mathrm{X}$ & \\
\hline $\begin{array}{l}\text { Decker and } \\
\text { Trusov }\end{array}$ & 2010 & Online reviews & & & & $X$ & \\
\hline Segel and Heer & 2010 & $\begin{array}{l}\text { Visualization and } \\
\text { learning }\end{array}$ & & $\mathrm{X}$ & & & \\
\hline $\begin{array}{l}\text { Mudambi and } \\
\text { Schuff }\end{array}$ & 2010 & Online reviews & & & & $\mathrm{X}$ & \\
\hline $\begin{array}{l}\text { Vermeulen and } \\
\text { Seegers }\end{array}$ & 2009 & Online reviews & & & $X$ & & \\
\hline Lee et al. & 2008 & Online reviews & & & $\mathrm{X}$ & & $\mathrm{X}$ \\
\hline Park et al. & 2007 & Online reviews & & & & $X$ & \\
\hline Mayer & 2003 & $\begin{array}{l}\text { Multimedia } \\
\text { learning }\end{array}$ & & $\mathrm{X}$ & & & \\
\hline Grewal et al. & 1997 & Advertisements & $\mathrm{X}$ & & & & \\
\hline Gotlieb and Sarel & 1991 & Advertisements & $\mathrm{X}$ & & & & \\
\hline $\begin{array}{l}\text { Gorn and } \\
\text { Weinberg }\end{array}$ & 1984 & Advertisements & $\mathrm{X}$ & & & & $\mathrm{X}$ \\
\hline Kelly & 1972 & Advertisements & & & & & $\mathrm{X}$ \\
\hline Current study & 2020 & Online reviews & $X$ & $X$ & $X$ & $X$ & $\mathrm{X}$ \\
\hline
\end{tabular}

organized (Appendix 1 Website 7). Thus, the required cognitive memory to process each of the product's information is less than mixed comparative reviews in text. In addition, a mixed comparative review is written by one person and thus avoids inconsistent consumer preferences that may exist between separate comparative reviews about two alternative products written by two consumers, which, in turn, result in review readers' confusion. Thus, 
H1b: The effect of review type on review value is moderated by the review presentation format, such that mixed comparative reviews are perceived to be more valuable if presented in tabular (vs. text) format than separate comparative reviews.

\section{Interaction Effect of Review Type and Review Valence}

In this section, we investigate how the effect of positive (vs. negative) review valence on product attitude is moderated by review type (mixed vs. separate comparative review). Consumers form beliefs about a product on the basis of the information they receive. In product attitude literature, positive information provided by an advertisement results in a positive product attitude, whereas negative product information degrades perceived product attitude (Lee et al. 2008). Such conformity is the tendency of opinions to establish a group norm and the tendency of individuals to comply with that norm.

Consistent with this line of literature, we also expect that positive review valance improves product attitude regardless of the review type; however, we predict that this impact is less when reviews are mixed (vs. separate) comparative. Advertising literature suggests that comparative advertisements do not necessarily improve consumers' attitude toward a target product. That is, negative information about an alternative product in an advertisement can be interpreted as a seller's attack against the competing product. This comparison can cause a lack of trust toward the advertisement and therefore less favorability for the target product (Gorn and Weinberg 1984; Gotlieb and Sarel 1991; Jain and Posavac 2004; Hsu 2018; We and Wen 2019). By adopting this concept to the context of comparative consumer reviews, when positive information about the target product is posted along with negative opinions regarding the competing product in a mixed comparative review, the positive review valence of the target product can be mitigated. Separate comparative reviews will not have such issues as the reviewers are provided by two different writers.

Our prediction can also be supported by attribution theory. According to this theory, consumers form attributions about an advertisement and a sponsored product on the basis of their evaluation of reasons why a claim has been made (Kelly 1972; Gotlieb and Sarel 1991; Jain and Posavac 2004; Hsu 2018; Wu and Wen 2019). In the context of comparative advertisements, Jain and Posavac (2004) found that users had a negative impression on advertisement believability about the sponsored brand of jeans when the advertiser disseminated negative information about a competitor. Such negative comparisons are discounted by advertisement viewers because consumers consider spreading competitors' negative information as acting in the interest of the advertiser (Jain and Posavac 2004). Thus, viewers will have less trust in the advertiser. We apply attribution theory and Jain and Posavac (2004)'s reasoning to our context. When readers are exposed to a negative comparison (i.e., negative review for an alternative product) in a mixed comparative review, they will perceive a higher manipulative intent from the review writer (Chang 2007). They form attributions about the target product with positive review valence and suspect the credibility level of the positive message (Wu and Wen 2019; Hsu 2018; Jain and Posavac 2004; Fein et al. 1993) in the mixed comparative review written by the review writer. As the credibility of the review about the target product is discounted, so does the product attitude. Thus, we propose the following:

H2: The effect of positive online review valence on product attitude toward a target product attenuates when the review is mixed (vs. separate) comparative.

Figure 1 illustrates the research model summarizing the proposed hypotheses.

\section{Study Setting}

We tested the aforementioned hypotheses through a laboratory experiment with a 3 (mixed comparative vs. separate comparative vs. regular review) x 2 (text vs. tabular presentation format) x 2 (positive vs. 
negative review valence) between-subject design. Accordingly, 12 different websites were built, each with seller-provided information about the products followed by either one or two reviews. The websites differed in the types of reviews, review presentation formats, and review valences. Table 3 presents the experimental designs and manipulations. Appendix 1 shows the screenshots of all 12 websites.

Figure 1. Research Model

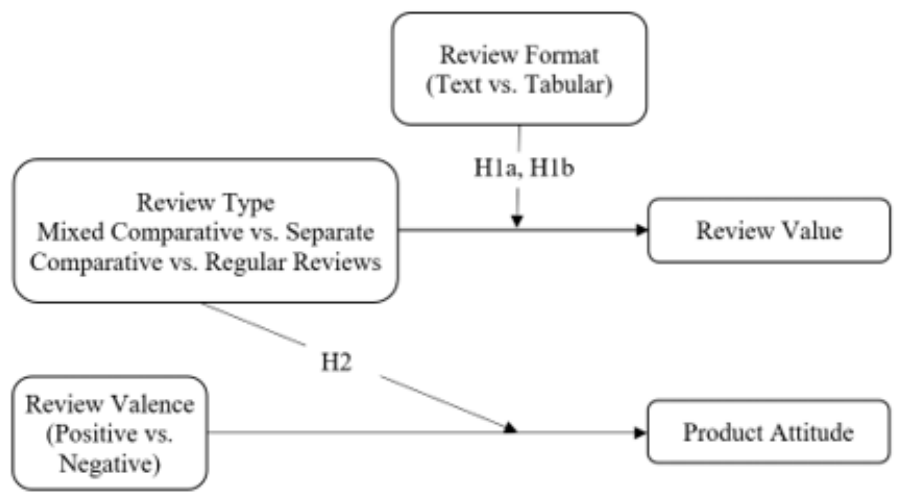

Prior to the main laboratory experimentation sessions, a pilot study was conducted wherein we first presented the survey to five participants, including professors and graduate students. This process helped us identify several opportunities for improvements. First, we confirmed that the product (i.e., mobile phone) presented on the websites is of interest to most people. Second, the participants suggested removing distracting items from the websites that may confound the results among the

Table 3. Experimental Designs and Manipulations

\begin{tabular}{|c|c|c|c|c|c|c|}
\hline $\begin{array}{l}\text { Website } \\
\text { Group }\end{array}$ & Review type & Format & Product & $\begin{array}{l}\text { iPhone } \\
\text { valence }\end{array}$ & $\begin{array}{c}\text { Samsung } \\
\text { valence }\end{array}$ & $\begin{array}{c}\text { Group } \\
\text { size }\end{array}$ \\
\hline 1 & Mixed comparative & \multirow[t]{6}{*}{ Text } & \multirow{4}{*}{$\begin{array}{l}\text { iPhone and } \\
\text { Samsung }\end{array}$} & Positive & Negative & 15 \\
\hline 2 & Mixed comparative & & & Negative & Positive & 18 \\
\hline 3 & Separate comparative & & & Positive & Negative & 18 \\
\hline 4 & Separate comparative & & & Negative & Positive & 16 \\
\hline 5 & Regular review & & \multirow{2}{*}{$\begin{array}{c}\text { iPhone } \\
\text { only }\end{array}$} & Positive & NA & 17 \\
\hline 6 & Regular review & & & Negative & NA & 17 \\
\hline 7 & Mixed comparative & \multirow[t]{6}{*}{ Tabular } & \multirow{4}{*}{$\begin{array}{l}\text { iPhone and } \\
\text { Samsung }\end{array}$} & Positive & Negative & 18 \\
\hline 8 & Mixed comparative & & & Negative & Positive & 17 \\
\hline 9 & Separate comparative & & & Positive & Negative & 17 \\
\hline 10 & Separate comparative & & & Negative & Positive & 16 \\
\hline 11 & Regular review & & \multirow{2}{*}{$\begin{array}{c}\text { iPhone } \\
\text { only }\end{array}$} & Positive & NA & 16 \\
\hline 12 & Regular review & & & Negative & NA & 16 \\
\hline
\end{tabular}


different experimental groups. Last, we refined the wording of ambiguous items and eliminated the redundant or confusing ones.

We advertised the experiment in four different classes representing students from three different colleges. Subjects were informed that they would receive extra credit for their participation. As an additional incentive, a $\$ 50$ Best Buy gift card was offered through a raffle drawing. We recruited 201 students from a large public university in Midwestern United States. All sessions were facilitated by the first author. The participants started by answering a demographic questionnaire. They were then assigned randomly to an experimental website. The experimental task for the participants was to read sellers' product information, followed by online reviews. Subsequently, the participants completed the experiment survey by answering the questions with measurement items for the dependent variables (e.g., review value and product attitude) and manipulation checks. On average, the participants spent 19 minutes to complete the experiment.

\section{Manipulation Checks and Measurement}

All variables in this study, such as valence, review value, attitude toward a product, review type, and review format, were measured using a seven-point Likert scale $(1=$ strongly disagree; $7=$ strongly agree). Table 4 shows the adopted measures and corresponding sources.

As a manipulation check for review type, subjects were asked to determine whether the assigned reviews were comparative by using a seven-point scale, with 1 for "not comparative" and 7 for "very comparative." Evidently, the subjects could distinguish regular reviews about one product, separate comparative reviews about two products, and mixed comparative reviews with averages of 2.92, 4.06, and 6.19 , respectively.

We also asked the participants to specify whether they can distinguish tabular-format reviews from text-format reviews, wherein "7" denotes tabular, and " 1 " denotes text. We used a Likert scale, rather than a dichotomous scale (which asks for "yes" or "no" only), given that each tabular review also includes text. The results are consistent with the study design, with average values of 5.70 for tabular reviews and 2.47 for text reviews. Finally, we checked the review valence regarding the study products, where "7" ("1") denotes "very positive" ("negative") reviews. Subjects rated the positive reviews about iPhone as 5.97 and negative reviews as 2.81 . Similarly, the average values for positive Samsung reviews were 5.70 and 2.61 for negative reviews.

\section{Data Analysis}

In this study, subjects were recruited from a large public university in the United States, including three colleges and 10 majors, thereby representing diverse backgrounds. After scanning through responses, nine subjects were excluded as their survey completion time was not long enough to assure enough attention to the survey questions. Among the 201 subjects, 155 were males, and 46 were females. The average age was 24.3. No significant difference was observed in age $(\mathrm{p}=0.38)$ and gender $(\mathrm{p}$ $=0.28$ ) distribution across the 12 groups. The Cronbach's alphas of 0.82 for familiarity with online reviews and 0.87 for familiarity with mobile phone attributes (product knowledge) attested to construct reliability (Fornell and Larcker 1981). To aid in interpreting the results, we report the average of the measurement items (Appendix 2) used in the scale for users' familiarity with online reviews and product knowledge, which have obtained 5.4 and 5.3, respectively, on a seven-point Likert scale.

We tested the proposed hypotheses by using statistical models, including covariance tests.

To support the reliability of individual items and the internal consistency of the constructs,

the Cronbach's alpha for each construct was calculated. All variables met the suggested tolerances (> .70, Fornell and Larcker 1981). Table 5 reports the results. To test the construct validity, the exploratory factor analysis of the review value and attitude toward the study products was performed with varimax rotation (Table 6). Without exception, all items loaded highly (loading ${ }^{3} 0.70$ ) on their associated factors, confirming the convergent validity of the factors. Two factors emerged with no cross-construct loadings exceeding 0.10 . That is, the loadings of a given construct's indicators were 
Table 4. Construct Definitions and Sample Measurements

\begin{tabular}{|c|c|c|c|}
\hline Variable & Variable definition & Survey question & Reference \\
\hline Valence & $\begin{array}{l}\text { Theme of an online review } \\
\text { that conveys either a generally } \\
\text { negative or positive sentiment of } \\
\text { a reviewer toward a product or } \\
\text { service }\end{array}$ & $\begin{array}{l}\text { - Do the provided reviews deliver positive } \\
\text { information about iPhone } 6 \text { / Samsung } \\
\text { Galaxy? } \\
\text { - How positive or negative did you perceive } \\
\text { the iPhone } 6 / \text { Samsung Galaxy reviews? }\end{array}$ & $\begin{array}{l}\text { Chen and } \\
\text { Lurie (2013) }\end{array}$ \\
\hline Review value & $\begin{array}{l}\text { Usefulness of the information } \\
\text { provided by a consumer review }\end{array}$ & $\begin{array}{l}\text { - How helpful was this review? } \\
\text { - Do you think the provided review is } \\
\text { helpful in making a purchase decision? }\end{array}$ & $\begin{array}{l}\text { Chen and } \\
\text { Lurie (2013) }\end{array}$ \\
\hline Review type & $\begin{array}{l}\text { 1) Mixed comparative reviews: } \\
\text { reviews written by one person } \\
\text { containing comparisons among } \\
\text { the attributes of two products. } \\
\text { 2) Separate comparative reviews: } \\
\text { two reviews written by two } \\
\text { different individuals. Each } \\
\text { review is about one different } \\
\text { product. } \\
\text { 3) Regular reviews: reviews } \\
\text { written by one individual } \\
\text { focusing on one product } \\
\text { only, common type in current } \\
\text { marketplaces }\end{array}$ & $\begin{array}{l}\text { Comparative reviews are those written by } \\
\text { one user to compare two different products } \\
\text { at the same time. Based on this definition, do } \\
\text { you think the website has any comparative } \\
\text { review? } \\
\text { - The consumer reviewed one cellphone } \\
\text { only. } \\
\text { - The consumer reviewed one cellphone in } \\
\text { relation to the other cellphone. } \\
\text { - The consumer reviewed two cellphones } \\
\text { separately. }\end{array}$ & $\begin{array}{l}\text { Based on } \\
\text { advertisement } \\
\text { literature (e.g., } \\
\text { Wilkie and } \\
\text { Farris 1975) }\end{array}$ \\
\hline $\begin{array}{l}\text { Review format } \\
\text { (tabular or text) }\end{array}$ & $\begin{array}{l}\text { In a tabular review, all attributes } \\
\text { are listed in table format, along } \\
\text { with the reviewer's comments for } \\
\text { each attribute. In a text review, } \\
\text { the attributes are discussed in } \\
\text { text format. }\end{array}$ & $\begin{array}{l}\text { - The website presented the consumer } \\
\text { review in tabular format. } \\
\text { - The consumer review was represented in a } \\
\text { table that contains the review. } \\
\text { - The consumer review was represented in } \\
\text { the form of several short paragraphs that } \\
\text { contain the relevant review. }\end{array}$ & $\begin{array}{l}\text { Based on } \\
\text { advertisement } \\
\text { literature } \\
\text { (Segel and } \\
\text { Heer 2010) }\end{array}$ \\
\hline Product attitude & $\begin{array}{l}\text { Beliefs consumers form about } \\
\text { a product on the basis of the } \\
\text { information they receive }\end{array}$ & $\begin{array}{l}\text { - I like the iPhone } 6 / \text { Samsung Galaxy better } \\
\text { after reading the review. } \\
\text { - After reading the review, I have formed } \\
\text { a favorable impression toward iPhone } 6 / \\
\text { Samsung Galaxy. }\end{array}$ & $\begin{array}{l}\text { Jiang and } \\
\text { Benbasat } \\
\text { (2007), and } \\
\text { Lee et al. } \\
\text { (2008) }\end{array}$ \\
\hline
\end{tabular}

higher than the loadings of any other. In all cases among the cross-loadings, the differences were greater than .80 . These findings had further supported the discriminant validity of these variables.

\section{Analysis of Proposed Hypotheses}

To test H1a and H1b, we conducted two ANCOVAs with review value as the dependent

variable to examine the interaction effect between review type and presentation format. The following variables were controlled in this study: participants' age, gender, product knowledge, and product importance. Table 7 and Figure 2 present the results. None of the control variables were significant $(\mathrm{p}>0.05)$, but the interaction effect was significant $(\mathrm{p}<0.05)$, thus supporting H1a. As illustrated in Figure 2, the y-axis shows the perceived review value, whereas the x-axis shows the review type. When reviews are in text format (solid line), regular reviews were not statistically different from mixed comparative reviews in terms of perceived review value $(\mathrm{p}>0.05)$; however, when reviews are presented in tabular format (dashed line), mixed comparative reviews were perceived to be more valuable than regular reviews ( $\mathrm{p}<0.05$, one-tailed). Figure 2 shows that tabular mixed comparative reviews were significantly better than text regular reviews $(\mathrm{p}<0.05)$. The difference between text 
Table 5. Internal Consistency of Constructs

\begin{tabular}{|l|c|}
\hline \multicolumn{1}{|c|}{ Construct } & Cronbach's Alpha \\
\hline iPhone Valence & .93 \\
\hline Samsung Valence & .97 \\
\hline Review Value & .98 \\
\hline Review Type & .76 \\
\hline Review Format & .78 \\
\hline Product Attitude- iPhone & .92 \\
\hline Product Attitude- Samsung & .97 \\
\hline
\end{tabular}

Table 6. Loading and Cross Loading of Measures

\begin{tabular}{|l|c|c|}
\hline & Review Value & Product Attitude \\
\hline Review Value 1 & $\mathbf{0 . 9 7 6}$ & 0.034 \\
\hline Review Value 2 & $\mathbf{0 . 9 8 5}$ & 0.018 \\
\hline Review Value 3 & $\mathbf{0 . 9 8 1}$ & 0.026 \\
\hline Product Attitude 1 & 0.027 & $\mathbf{0 . 9 5 9}$ \\
\hline Product Attitude 2 & 0.045 & $\mathbf{0 . 9 2 2}$ \\
\hline Product Attitude 3 & 0.003 & $\mathbf{0 . 9 1 3}$ \\
\hline
\end{tabular}

versus tabular format for regular reviews was not significant ( $p>0.05)$. By contrast, the difference between text versus tabular format for comparative reviews was large $(\mathrm{p}<0.001)$.

Solid line: text format.

Dashed line: tabular format

Note: Effect of review type on review value with the format as moderating factor

Another ANCOVA was performed to test H1b. Table 8 and Figure 3 report the analysis results. Table 8 reveals that the interaction effect between review type and presentation format was significant. Similar to Figure 2, the y-and $x$-axes in Figure 3 represent review value and type, respectively. In the text format (solid line in Figure 3), separate comparative reviews were perceived to be more valuable than mixed comparative reviews ( $\mathrm{p}<0.01$ ); however, in tabular format (dashed line), no difference existed between mixed and separate comparative reviews $(p>0.05)$. In summary, the effect of review type on review value is moderated by the review presentation format, such that mixed comparative reviews in text (vs. tabular) format are perceived to be less valuable than separate comparative reviews, thereby supporting H1b. In addition, we observed that the review value difference between text and tabular format for separate comparative review was small, indicating no significant difference ( $\mathrm{p}>$ 0.05). By contrast, when reviews are mixed, the tabular format was found better than text format in review value $(\mathrm{p}<0.01)$.

To test $\mathrm{H} 2$, we ran two separate regressions as we have two dependent variables (one for product attitude toward iPhone, the other for Samsung). Tables 9 and 10 illustrate the regression results for iPhone and Samsung, respectively. Review valence had a significant main effect on product attitudes for both products $(\mathrm{p}<0.001)$. That is, regardless of review type, positivity in review valence results in high product favorability. The interaction effect between review valence and review type was significant for both products $(\mathrm{p}<0.05)$. In mixed comparative reviews, the negative information on 
Table 7. ANCOVA Summary Table for Review Value H1a

\begin{tabular}{|l|r|r|r|r|r|}
\hline Dependent variable: review value & & & & \\
\hline Source & \multicolumn{1}{|c|}{ Sum of squares } & \multicolumn{1}{c|}{ df } & Mean square & F & Sig. \\
\hline Corrected Model & $65.800^{\mathrm{a}}$ & 7 & 9.400 & 4.093 & 0.000 \\
\hline Intercept & 6.085 & 1 & 6.085 & 2.650 & 0.106 \\
\hline Product Knowledge & 0.330 & 1 & 0.330 & 0.144 & 0.705 \\
\hline Gender & 1.354 & 1 & 1.354 & 0.589 & 0.444 \\
\hline Age & 3.461 & 1 & 3.461 & 1.507 & 0.222 \\
\hline Product Importance & 3.702 & 1 & 3.702 & 1.612 & 0.207 \\
\hline Review Type & 0.002 & 1 & 0.002 & 0.001 & 0.977 \\
\hline Review Format & 29.951 & 1 & 29.951 & 13.040 & 0.000 \\
\hline Review Type * Format & 10.650 & 1 & 10.650 & 4.637 & 0.033 \\
\hline Error & 289.395 & 126 & 2.297 & & \\
\hline Total & 3038.778 & 134 & & & \\
\hline Corrected Total & 355.195 & 133 & & & \\
\hline
\end{tabular}

Note: H1a was tested on the basis of the subjects assigned to groups with regular reviews about one product and groups with mixed comparative reviews

Figure 2. Mixed Comparative Reviews vs. Regular Reviews about One Product

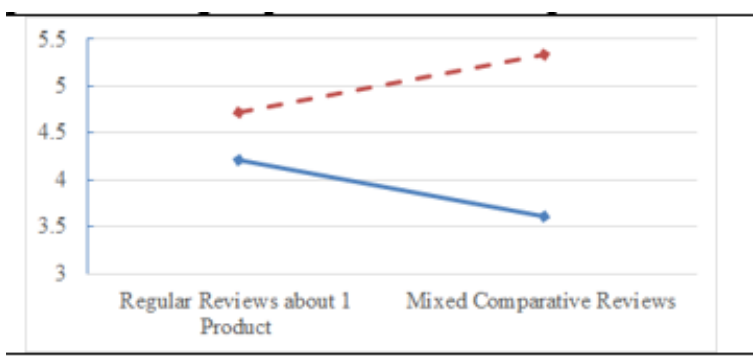

Figure 3. Mixed vs. Separate Comparative Reviews

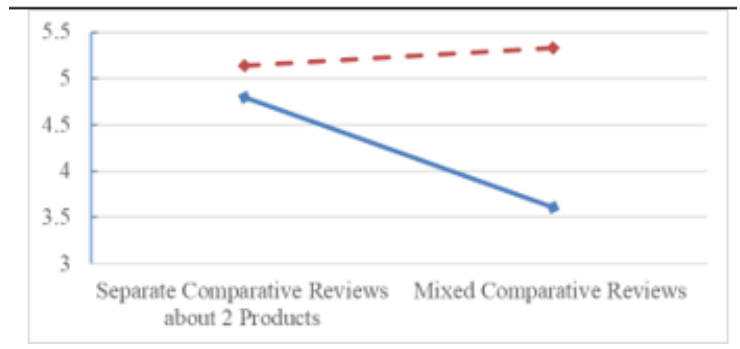


Table 8. ANCOVA Summary Table for Review Value H1b

\begin{tabular}{|l|r|r|r|r|r|}
\hline Dependent variable: review value & & & & \\
\hline Source & Sum of squares & \multicolumn{1}{|c|}{ df } & Mean square & F & Sig. \\
\hline Corrected Model & $74.393^{\mathrm{a}}$ & 7 & 10.628 & 4.457 & 0.000 \\
\hline Intercept & 14.408 & 1 & 14.408 & 6.043 & 0.015 \\
\hline Product Knowledge & 1.219 & 1 & 1.219 & 0.511 & 0.476 \\
\hline Gender & 1.104 & 1 & 1.104 & 0.463 & 0.497 \\
\hline Age & 0.155 & 1 & 0.155 & 0.065 & 0.799 \\
\hline Produce Importance & 11.596 & 1 & 11.596 & 4.863 & 0.029 \\
\hline Review Type & 10.299 & 1 & 10.299 & 4.319 & 0.040 \\
\hline Review Format & 25.325 & 1 & 25.325 & 10.621 & 0.001 \\
\hline Review Type*Format & 13.544 & 1 & 13.544 & 5.680 & 0.019 \\
\hline Error & 302.828 & 127 & 2.384 & & \\
\hline Total & 3398.667 & 135 & 134 & & \\
\hline Corrected Total & 377.221 & 134 & & & \\
\hline
\end{tabular}

Note: $\mathrm{H} 1 \mathrm{~b}$ was tested on the basis of the subjects assigned to groups with separate comparative reviews and groups with mixed comparative reviews.

Table 9. Regression Model for H2 (product attitude for iPhone)

\begin{tabular}{|c|c|c|c|c|c|c|}
\hline & & \multicolumn{2}{|c|}{$\begin{array}{c}\text { Unstandardized } \\
\text { Coefficients }\end{array}$} & \multirow{2}{*}{$\begin{array}{c}\begin{array}{c}\text { Standardized } \\
\text { Coefficients }\end{array} \\
\text { Beta } \\
\end{array}$} & \multirow[b]{2}{*}{$\mathbf{t}$} & \multirow[b]{2}{*}{ Sig. } \\
\hline \multicolumn{2}{|c|}{ Model } & B & Std. Error & & & \\
\hline \multirow[t]{8}{*}{1} & (Constant) & 1.300 & 1.291 & & 1.006 & 0.316 \\
\hline & Age & 0.023 & 0.176 & 0.009 & 0.128 & 0.898 \\
\hline & Gender & -0.023 & 0.323 & -0.005 & -0.073 & 0.942 \\
\hline & Product Importance & -0.021 & 0.122 & -0.012 & -0.172 & 0.864 \\
\hline & Product Knowledge & 0.256 & 0.126 & 0.145 & 2.036 & 0.044 \\
\hline & Review Type & 0.609 & 0.354 & 0.158 & 1.719 & 0.088 \\
\hline & iPhone Valence & 3.103 & 0.364 & 0.804 & 8.525 & 0.000 \\
\hline & iPhone Valence* Review Type & -1.276 & 0.521 & -0.284 & -2.448 & 0.016 \\
\hline
\end{tabular}

the alternative product induces a potential buyer to feel biased regarding the target product; therefore, product favorability still increases but not as much as in the case of separate comparative reviews (Figures 4 and 5). The negative coefficients for the interaction terms in both models support this argument.

\section{DISCUSSION}

Overall, the results supported all the hypothesized relationships in our proposed model. 
Table 10. Regression Model for H2 (product attitude for Samsung)

\begin{tabular}{|c|c|c|c|c|c|c|}
\hline \multirow{2}{*}{\multicolumn{2}{|c|}{ Model }} & \multicolumn{2}{|c|}{ Unstandardized Coefficients } & \multirow{3}{*}{$\begin{array}{c}\begin{array}{c}\text { Standardized } \\
\text { Coefficients }\end{array} \\
\text { Beta }\end{array}$} & \multirow{3}{*}{$\begin{array}{c}\mathbf{t} \\
1.845\end{array}$} & \multirow{3}{*}{$\begin{array}{c}\text { Sig. } \\
0.067\end{array}$} \\
\hline & & \multirow{2}{*}{$\begin{array}{c}\text { B } \\
2.038\end{array}$} & \multirow{2}{*}{$\frac{\text { Std. Error }}{1.104}$} & & & \\
\hline 1 & (Constant) & & & & & \\
\hline & Age & 0.127 & 0.148 & 0.055 & 0.861 & 0.391 \\
\hline & Gender & -0.055 & 0.271 & -0.014 & -0.204 & 0.839 \\
\hline & $\begin{array}{l}\text { Product } \\
\text { Importance }\end{array}$ & -0.010 & 0.103 & -0.006 & -0.097 & 0.923 \\
\hline & $\begin{array}{l}\text { Product } \\
\text { Knowledge }\end{array}$ & -0.069 & 0.106 & -0.043 & -0.654 & 0.514 \\
\hline & Review Type & 0.787 & 0.320 & 0.226 & 2.462 & 0.015 \\
\hline & $\begin{array}{l}\text { Samsung } \\
\text { Valence }\end{array}$ & 2.899 & 0.306 & 0.832 & 9.478 & 0.000 \\
\hline & $\begin{array}{l}\text { Samsung } \\
\text { Valence* } \\
\text { Review Type }\end{array}$ & -0.897 & 0.438 & -0.226 & -2.047 & 0.043 \\
\hline
\end{tabular}

Figure 4. Moderating Effect of Review Valence on Product Attitude toward iPhone

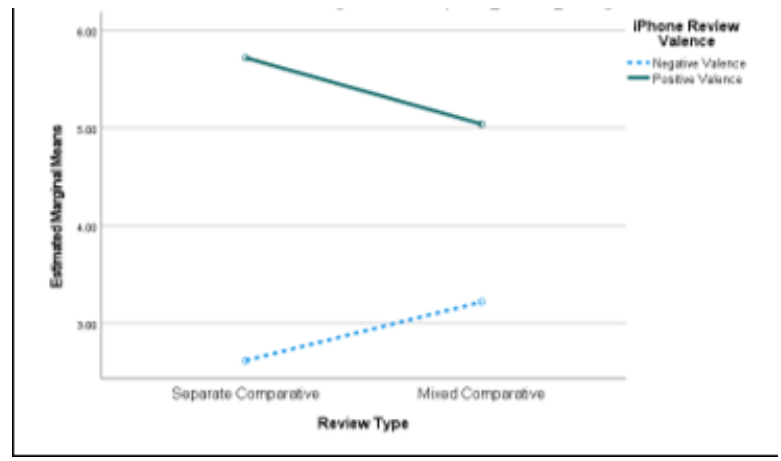

Figure 5. Moderating Effect of Review Valence on Product Atitude toward Samsung

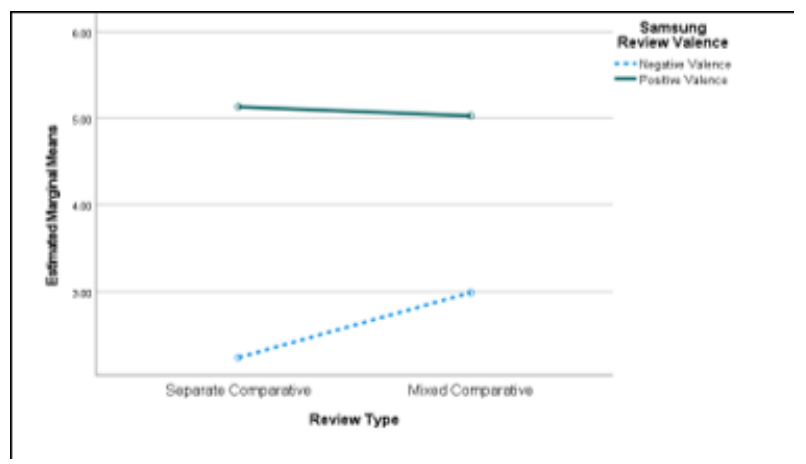


As one of the main objectives of this study, we introduce a new method of recording and presenting online reviews that can increase review value. The results of $\mathrm{H} 1 \mathrm{a}$ and $\mathrm{H} 1 \mathrm{~b}$, which focused on interactions between review types and presentation formats, are consistent with the consolidation of visualization effects (Segel and Heer 2010), cognitive load (Sweller 1988), and cognitive theory of multimedia learning (Mayer and Moreno 2003; Sorden 2012). A textual mixed comparative review does not lead to higher review value than a regular or separate comparative review, given that the former contains more unorganized information and requires more cognitive load than the latter. Meanwhile, categorizing information in tabular format, predicted by the cognitive theory of multimedia learning, was confirmed to help a buyer capture highly informative content with less memory load. Therefore, valuable review information can be delivered to the buyer by providing a mixed comparative review in tabular format.

The proposed mixed comparative review in tabular format is an innovative online review presentation. The closest field of study to this research is comparative advertisements in various media, such as television and radio (Grewal et al. 1997; Byun and Jang 2018; Soscia et al. 2010). Advertisement and online reviews are different as one's content is generated by sellers, and the other is created by consumers. When comparative online reviews are presented in tabular format, their positive effects are similar to those of comparative advertisements (Hill et al. 2004). By contrast, when mixed comparative reviews are presented in plain text format, their superior effects weaken. These results are different from advertisement literature, which shows that comparative advertisements are more persuasive than noncomparative advertisements.

Although not hypothesized, a direct relationship between presentation format and review value was found ( $\mathrm{p}<0.001$ ), as shown in Tables 7 and 8. These findings imply the importance of the proposed tabular format used in presenting online reviews, given the reduction of the cognitive load with the tabular format based on cognitive load theory. This outcome is consistent with prior studies found in other contexts, such as learning and education (Segel and Heer 2010; Sorden 2012). However, to the best of our knowledge, our study is one of the pioneers to introduce this tabular format to the online review context and examine its significance.

$\mathrm{H} 2$ proposes that the positive valence of online reviews results in high product favorability regardless of review type; however, in a mixed comparative review, negative information about an alternative product induces a buyer to perceive that the review is biased toward the target product. Thus, product favorability still increases, but not as much as regular or separate comparative reviews. In this study, we adopted attribution theory (Kelly 1972) in comparative advertisement literature as a theoretical lens to examine the effect of review valence on product attitude when reviews are mixed comparative. When a potential buyer reads an online review with positive valence about the target product and negative information about the competing product, the entire message is considered a negative comparison (Jain and Posavac 2004). In the case of negative comparisons, which have been introduced in this study as mixed comparative reviews, readers attribute the target product's positive message as manipulated and accordingly suspect the reviewer's sincerity (We and Wen 2019; Hsu 2018; Jain and Posavac 2004; Fein et al. 1993). They may suspect that the review writer has a biased view of the product or opted not to report or disclose certain factors or points of view. Such suspicion can negatively affect readers' attitude toward the target product.

Although the effect of review valence on product attitude is examined in the context of comparative reviews for the first time in this research, the results are consistent with comparative advertisement literature where negative information about an alternative product does not necessarily improve the attitude toward the target product (Gotlieb and Sarel 1991; Jain and Posavac 2004; Chang 2007; Hsu 2018; Wu and Wen 2019). For example, Gotlieb and Sarel (1991) empirically found that users doubt the advertisement credibility of a sponsored brand when another brand of video cassette is bad-mouthed. Similarly, Hsu (2018) revealed that viewers have less trust in the sponsored brands of a mobile phone carrier when negative messages about its competitor are also stated. Their attitude 
toward the target product is reduced due to the lack of trust in advertisement credibility when negative information about the competing product is disseminated.

\section{THEORETICAL CONTRIBUTIONS}

This study provides several theoretical contributions. First, we advance the online consumer review literature by proposing the mixed comparative review and examining its effect on review value. Extant consumer review literature has mainly investigated the influences of review volume (Guo and Zhou 2016), review length (Mudambi and Schuff 2010), review valance (Filieri et al. 2019; Chen and Lurie 2013), and review star rating ( $\mathrm{Li}$ et al. 2020). To the best of our knowledge, this study is the first to propose the review type of mixed comparative reviews. We contribute to the literature by proposing mixed comparative reviews and subsequently categorizing product attributes in tabular format as a new type of marketing tool, which can be used to improve the value of online reviews. The results of this study expand the values of comparative ads into consumer reviews.

Second, this study contributes to the understanding of comparative content literature. Advertisement literature shows that comparative advertisements are generally more valuable (Grewal et al. 1997; Byun and Jang 2018; Soscia et al. 2010) than noncomparative advertisements. However, by applying this notion to online consumer reviews, comparative reviews are found not necessarily more valuable than noncomparative reviews. When reviews are presented in text format, separate comparative reviews are perceived to be more valuable than mixed comparative reviews. By contrast, mixed comparative reviews presented in tabular format with categorized information about product attributes are perceived to be more valuable than text reviews with unorganized information about product attributes.

Third, we draw upon and contribute back to the cognitive theory of multimedia learning (Mayer and Moreno 2003). Comparative reviews help buyers extract more information than regular online reviews, and the tabular format helps buyers reduce their cognitive load in digesting review information. Thus, we study the interaction between an innovative review type and presentation format. The findings contribute to these theories by extending the application to the context of contemporary online consumer review, particularly with mixed comparative reviews.

Finally, we extend attribution theory to the context of comparative consumer reviews by studying the effect of review valence of the target product (vs. competing alternative product) on product attitude. Negative information about the alternative product in mixed comparative reviews reduces the positive effect of review valence on product attitude toward the target product. This finding is supported by attribution theory (Kelly 1972; Gotlieb and Sarel 1991; Jain and Posavac 2004; Chang 2007; Hsu 2018; Wu and Wen 2019). However, this finding challenges previous research asserting that positive valence in reviews always results in high product attitude (Lee at al. 2008). Our finding is reasonable, given that the negative review valence about the alternative product may trigger buyers' suspicion on reviewers' motive in writing the reviews.

\section{PRACTICAL CONTRIBUTIONS}

This study also has several implications for practitioners. For many years, comparative advertisements have been used to convince buyers to choose supported products, and the majority of studies in academia and business sectors have shown the effectiveness of such advertisements. After introducing consumer reviews as a new and well-accepted marketing tool, we felt the need to study this field to determine the value of comparative consumer reviews.

The findings of this research can be used by business model developers in online marketplaces to create a new online review infrastructure. Consequently, businesses can convince consumers with experience on alternative products to share their opinions by using mixed comparative reviews in tabular format if they experience using target and alternative products. Although certain online 
websites, such as CNET, have already performed this strategy, they obtain the opinions of experts and not those of regular users. Our study results reveal that such comparative reviews in tabular format provide the most review value.

The results likewise indicate that the presence of a negative opinion about an alternative product negatively affects a buyer's attitude toward the competing product that has a positive valence. That is, negative information about one product in mixed comparative reviews reduces the creation of a positive attitude toward the competing product that has a positive valence. This finding can help marketing experts decide when mixed comparative reviews are more appropriate than regular reviews. When a consumer wants to express his/her opinions about alternative products on two sides of the satisfaction spectrum, regular reviews about either one or two products can be more appropriate in terms of product attitude. However, when the consumer's opinions about alternative products are only slightly different and cannot be distinguished, mixed comparative reviews should be more valuable and can simultaneously create greater product attitude than regular reviews.

\section{LIMITATIONS AND FUTURE RESEARCH}

The limitations of this research are acknowledged, and possible future research suggestions are indicated as follows: First, the parsimony of our proposed model suggests that certain additional variables may help explain key variables and moderate the strength of relationships within the model. For example, product type, product knowledge (Xu et al. 2011), and personal relevance may moderate the impacts of review type and format. Second, consumers' actual purchase behavior is not examined in this study. Such research can further advance toward recognizing the values of review type and format in online marketing. Therefore, future researchers should study the effect of value on consumers' actual purchase behavior. Third, our proposed review format is lacking in existing sellers' websites. Although our new review presentation format is the main contribution of this study, this limitation hinders us from validating our research by using existing real reviews. Field experiments are necessary when online merchants adopt our proposed review presentation.

Fourth, the participants were mostly university students. Among the 201 participants, 195 had smartphones; 159 had either an iPhone or Samsung. Thus, reading online reviews and shopping for smartphones were common occurrences and a natural fit for our research design. Over $60 \%$ of the students in the university had full- or part-time jobs. In addition, $32.3 \%$ of the participants were over 26 years old, whereas $10.4 \%$ were over 31 years old. Nevertheless, readers should exercise caution in generalizing the results of this study to other demographic groups. To generalize the experimental results, conducting additional studies with different subject demographics and settings may be necessary.

The final limitation lies within the failure of the study to control for the review length in the manipulation of the positive versus negative reviews of products. Prior research indicated that review length does not have a significant effect on certain dependent variables, such as satisfaction with review (Adewoyin et al. 2016), purchase intention (Lin et al. 2007), attitude toward review (Lui et al. 2015), and review helpfulness (Korfiatis et al. 2012). However, review length may likely affect users' judgment on review value and buyers' attitude toward a product. Thus, rigorously including this factor in the experiment design to verify its role will be prudent for future research.

\section{CONCLUSION}

Guided by cognitive load theory and visualization literature, this study proposes a new and effective method for collecting and presenting online consumer reviews, namely, mixed comparative online reviews in tabular format. We compare this review type to separate comparative and regular reviews. We develop 12 websites containing different types of reviews and analyze the data collected from 201 participants. The results show that mixed comparative reviews do not create any advantage over 
separate comparative or regular reviews when reviews are presented in text format. However, when reviews are in tabular format, mixed comparative reviews exhibit a greater review value to potential buyers than regular reviews. Moreover, although positive review valence results in high product attitude, this effect weakens in mixed comparative reviews when one product has a positive valence, whereas the alternative product has a negative valence.

\section{ACKNOWLEDGEMENT}

This work was partially supported by the Strategic Research Grant at the City University of Hong Kong (Grant No. 7005473) and the Hong Kong Research Grant Council (Grant No. 9042729). 


\section{REFERENCES}

Adewoyin, O., Araya, R., \& Vassileva, J. (2016, June). Peer review in mentorship: perception of the helpfulness of review and reciprocal ratings. In International Conference on Intelligent Tutoring Systems (pp. 286-293). Springer. doi:10.1007/978-3-319-39583-8_31

Al-Debei, M. M., Akroush, M. N., \& Ashouri, M. I. (2015). Consumer attitudes towards online shopping. Internet Research, 25(5), 707-733. doi:10.1108/IntR-05-2014-0146

Bag, S., Tiwari, M. K., \& Chan, F. T. (2019). Predicting the consumer's purchase intention of durable goods: An attribute-level analysis. Journal of Business Research, 94, 408-419. doi:10.1016/j.jbusres.2017.11.031

Bazerman, M. H. (2001). Consumer research for consumers. The Journal of Consumer Research, 27(4), 499-504. doi: $10.1086 / 319624$

Byun, J., \& Jang, S. S. (2018). “To compare or not to compare?": Comparative appeals in destination advertising of ski resorts. Journal of Destination Marketing \& Management, 10, 143-151. doi:10.1016/j.jdmm.2018.09.003

Chang, C. (2007). The relative effectiveness of comparative and noncomparative advertising: Evidence for gender differences in information-processing strategies. Journal of Advertising, 36(1), 21-35. doi:10.2753/ JOA0091-3367360102

Chen, J., Teng, L., Yu, Y., \& Yu, X. (2016). The effect of online information sources on purchase intentions between consumers with high and low susceptibility to informational influence. Journal of Business Research, 69(2), 467-475. doi:10.1016/j.jbusres.2015.05.003

Chen, K., \& Deng, T. (2016). Research on the green purchase intentions from the perspective of product knowledge. Sustainability, 8(9), 943. doi:10.3390/su8090943

Chen, Y., \& Xie, J. (2008). Online consumer review: Word-of-mouth as a new element of marketing communication mix. Management Science, 54(3), 477-491. doi:10.1287/mnsc.1070.0810

Chen, Z., \& Lurie, N. H. (2013). Temporal contiguity and negativity bias in the impact of online word of mouth. JMR, Journal of Marketing Research, 50(4), 463-476. doi:10.1509/jmr.12.0063

Christozov, D., Chukova, S., \& Mateev, P. (2009). On two types of warranties: Warranty of malfunctioning and warranty of misinforming. Asia-Pacific Journal of Operational Research, 26(3), 399-420. doi:10.1142/ S0217595909002274

Connors, L., Mudambi, S. M., \& Schuff, D. (2011, January). Is it the review or the reviewer? A multi-method approach to determine the antecedents of online review helpfulness. In 2011 44th Hawaii International Conference on System Sciences (pp. 1-10). IEEE.

D’Acunto, D., Tuan, A., \& Dalli, D. (2020). Are Online Reviews Helpful for Consumers? Big Data Evidence From Services Industry. In Exploring the Power of Electronic Word-of-Mouth in the Services Industry (pp. 198-216). IGI Global. doi:10.4018/978-1-5225-8575-6.ch012

Decker, R., \& Trusov, M. (2010). Estimating aggregate consumer preferences from online product reviews. International Journal of Research in Marketing, 27(4), 293-307. doi:10.1016/j.jjresmar.2010.09.001

Dinkelman, T., \& Ranchhod, V. (2012). Evidence on the impact of minimum wage laws in an informal sector: Domestic workers in South Africa. Journal of Development Economics, 99(1), 27-45. doi:10.1016/j. jdeveco.2011.12.006

Fein, S., Hilton, J. L., \& Miller, D. T. (1989). The effects of suspicion on dispositional inference. In 61st annual meeting of the Midwestern Psychological Association, Chicago, IL.

Filieri, R., Raguseo, E., \& Vitari, C. (2019). What moderates the influence of extremely negative ratings? The role of review and reviewer characteristics. International Journal of Hospitality Management, 77, 333-341. doi:10.1016/j.jhm.2018.07.013

Fornell, C., \& Larcker, D. F. (1981). Evaluating structural equation models with unobservable variables and measurement error. JMR, Journal of Marketing Research, 18(1), 39-50. doi:10.1177/002224378101800104 
Gorn, G. J., \& Weinberg, C. B. (1984). The impact of comparative advertising on perception and attitude: Some positive findings. The Journal of Consumer Research, 11(2), 719-727. doi:10.1086/209008

Gotlieb, J. B., \& Sarel, D. (1991). Comparative advertising effectiveness: The role of involvement and source credibility. Journal of Advertising, 20(1), 38-45. doi:10.1080/00913367.1991.10673205

Grewal, D., Kavanoo, S., Fern, E. F., Costley, C., \& Barnes, J. (1997). Comparative versus noncomparative advertising: A meta-analysis. Journal of Marketing, 61(4), 1-15. doi:10.1177/002224299706100401

Guo, B., \& Zhou, S. (2016). Understanding the impact of prior reviews on subsequent reviews: The role of rating volume, variance and reviewer characteristics. Electronic Commerce Research and Applications, 20, 147-158. doi:10.1016/j.elerap.2016.10.007

Hill, D. J., Blodgett, J., Baer, R., \& Wakefield, K. (2004). An investigation of visualization and documentation strategies in services advertising. Journal of Service Research, 7(2), 155-166. doi:10.1177/1094670504268449

Hsu, T. (2018). The effects of advertising valence on comparative advertising: The roles of counterarguments. Journal of Marketing Development and Competitiveness, 12(1).

Jackson, D. W. Jr, Brown, S. W., \& Harmon, R. R. (1979). Comparative Magazine Advertisements. Journal of Advertising Research, 19(12), 21-26.

Jain, S. P., \& Posavac, S. S. (2004). Valenced comparisons. JMR, Journal of Marketing Research, 41(1), 46-58. doi:10.1509/jmkr.41.1.46.25080

Jiang, Z., \& Benbasat, I. (2007). Investigating the influence of the functional mechanisms of online product presentations. Information Systems Research, 18(4), 454-470. doi:10.1287/isre.1070.0124

Kelly, H. H. (1972). Attributions in Social Interaction. In Attribution: Perceiving the Causes of Behavior. General Learning Press.

Korfiatis, N., García-Bariocanal, E., \& Sánchez-Alonso, S. (2012). Evaluating content quality and helpfulness of online product reviews: The interplay of review helpfulness vs. review content. Electronic Commerce Research and Applications, 11(3), 205-217. doi:10.1016/j.elerap.2011.10.003

Lavidge, R. J., \& Steiner, G. A. (1961). A model for predictive measurements of advertising effectiveness. Journal of Marketing, 25(6), 59-62. doi:10.1177/002224296102500611

Lee, J., Park, D. H., \& Han, I. (2008). The effect of negative online consumer reviews on product attitude: An information processing view. Electronic Commerce Research and Applications, 7(3), 341-352. doi:10.1016/j. elerap.2007.05.004

Li, Q., Zeng, D. D., Xu, D. J., Liu, R., \& Yao, R. (2020). Understanding and Predicting Users' Rating Behavior: A Cognitive Perspective. INFORMS Journal on Computing, ijoc.2019.0919. doi:10.1287/ijoc.2019.0919

Lin, T. M., Huang, Y. K., \& Yang, W. I. (2007). An experimental design approach to investigating the relationship between Internet book reviews and purchase intention. Library \& Information Science Research, 29(3), $397-415$. doi:10.1016/j.lisr.2007.04.010

Liu, P. J., Lamberton, C., \& Haws, K. L. (2015). Should firms use small financial benefits to express appreciation to consumers? Understanding and avoiding trivialization effects. Journal of Marketing, 79(3), 74-90. doi:10.1509/ jm.14.0091

Mayer, R. E., \& Moreno, R. (2003). Nine Ways to Reduce Cognitive Load in Multimedia Learning. Educational Psychologist, 38(1), 43-52. doi:10.1207/S15326985EP3801_6

Moore, D. M. M., Burton, J. K., \& Myers, R. J. (2004). Multiple-Channel Communication: The Theoretical and Research Foundations of Multimedia. In Handbook of research for educational communication and technology. Macmillan.

Mudambi, S. M., \& Schuff, D. (2010). Research note: What makes a helpful online review? A study of customer reviews on Amazon. com. MIS Quarterly, 185-200.

Paharia, N., Avery, J., \& Keinan, A. (2014). Positioning brands against large competitors to increase sales. JMR, Journal of Marketing Research, 51(6), 647-656. doi:10.1509/jmr.13.0438 
Pan, X., Hou, L., Liu, K., \& Niu, H. (2018). Do reviews from friends and the crowd affect online consumer posting behaviour differently? Electronic Commerce Research and Applications, 29, 102-112. doi:10.1016/j. elerap.2018.01.007

Park, D. H., Lee, J., \& Han, I. (2007). The effect of online consumer reviews on consumer purchasing intention: The moderating role of involvement. International Journal of Electronic Commerce, 11(4), 125-148. doi:10.2753/ JEC1086-4415110405

Segel, E., \& Heer, J. (2010). Narrative visualization: Telling stories with data. IEEE Transactions on Visualization and Computer Graphics, 16(6), 1139-1148. doi:10.1109/TVCG.2010.179 PMID:20975152

Severin, W. (1967). Another look at cue summation. AV Communication Review, 15(3), 233-245.

Singh, J. P., Irani, S., Rana, N. P., Dwivedi, Y. K., Saumya, S., \& Roy, P. K. (2017). Predicting the "helpfulness" of online consumer reviews. Journal of Business Research, 70, 346-355. doi:10.1016/j.jbusres.2016.08.008

Smith, D., Menon, S., \& Sivakumar, K. (2005). Online peer and editorial recommendations, trust, and choice in virtual markets. Journal of Interactive Marketing, 19(3), 15-37. doi:10.1002/dir.20041

Sorden, S. D. (2012). The cognitive theory of multimedia learning. Handbook of Educational Theories, 1, 31.

Soscia, I., Girolamo, S., \& Busacca, B. (2010). The effect of comparative advertising on consumer perceptions: Similarity or differentiation? Journal of Business and Psychology, 25(1), 109-118. doi:10.1007/s10869-0099130-4

Sweller, J. (1988). Cognitive load during problem solving: Effects on learning. Cognitive Science, 12(2), $257-285$. doi:10.1207/s15516709 $\operatorname{cog} 1202 \_4$

Vali, H., Xu, D., \& Yildirim, M. (2015). The effect of conflicting consumer reviews on the accuracy of a purchase decisions. Proceedings of Americas Conference on Information Systems.

Vermeulen, I. E., \& Seegers, D. (2009). Tried and tested: The impact of online hotel reviews on consumer consideration. Tourism Management, 30(1), 123-127. doi:10.1016/j.tourman.2008.04.008

Wilkie, W. L., \& Farris, P. W. (1975). Comparison advertising: Problems and potential. Journal of Marketing, 39(4), 7-15. doi:10.1177/002224297503900402

Wood, R. E. (1986). Task complexity: Definition of the construct. Organizational Behavior and Human Decision Processes, 37(1), 60-82. doi:10.1016/0749-5978(86)90044-0

Wu, L., \& Wen, T. J. (2019). Exploring the impact of affect on the effectiveness of comparative versus noncomparative advertisements. International Journal of Advertising, 38(2), 296-315. doi:10.1080/0265048 7.2018.1454020

Xu, J. D., Benbasat, I., \& Cenfetelli, R. (2011). The effects of service and consumer product knowledge on online customer loyalty. Journal of the Association for Information Systems, 12(11), 1. doi:10.17705/1jais.00279

Xu, J. D., Benbasat, I., \& Cenfetelli, R. T. (2013). Integrating service quality with system and information quality: An empirical test in the e-service context. Management Information Systems Quarterly, 37(3), 777-794. doi:10.25300/MISQ/2013/37.3.05

Yin, D., Mitra, S., \& Zhang, H. (2016). When do consumers value positive vs. negative reviews? An empirical investigation of confirmation bias in online word of mouth. Information Systems Research, 27(1), $131-144$. doi:10.1287/isre.2015.0617 
Journal of Global Information Management

Volume 29 • Issue 6

\section{APPENDIX 1.}

\section{Screenshots of Websites Showing Various Treatments}

Figure 6.

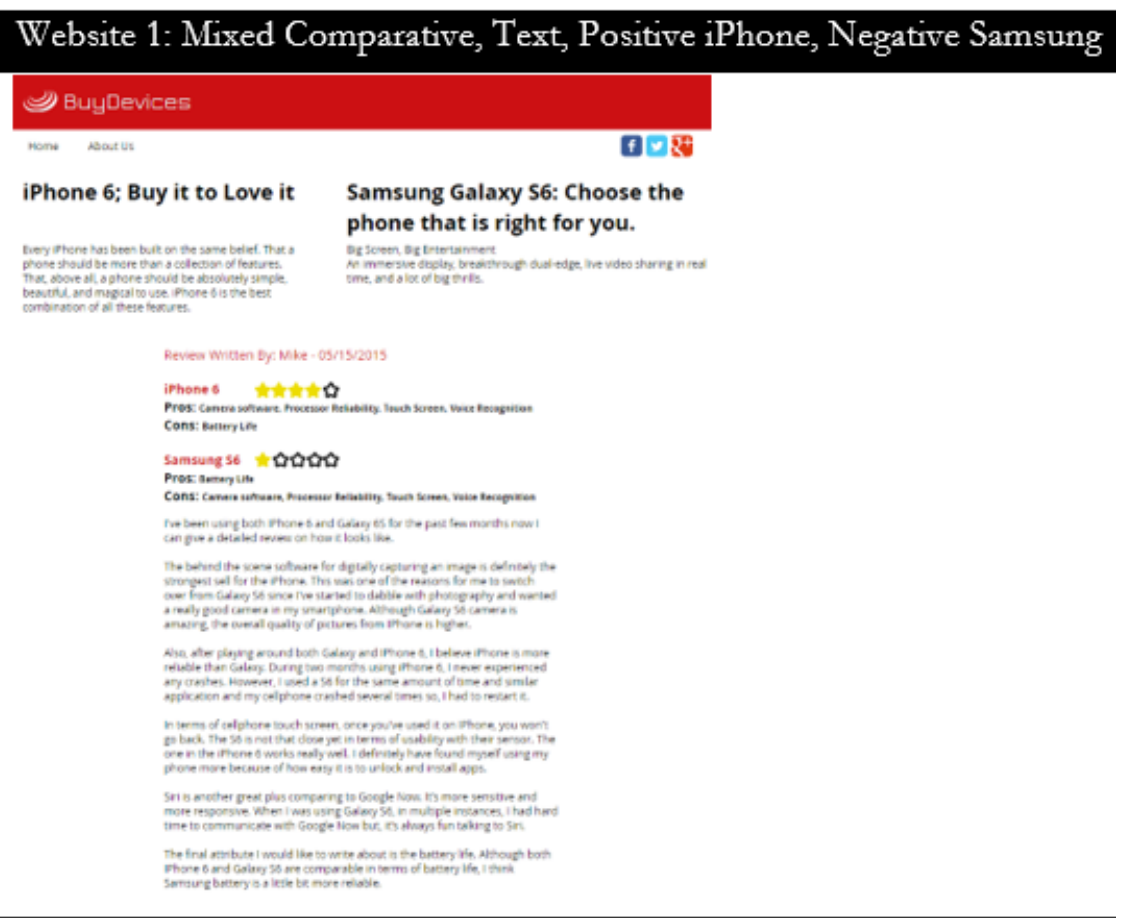


Figure 7.

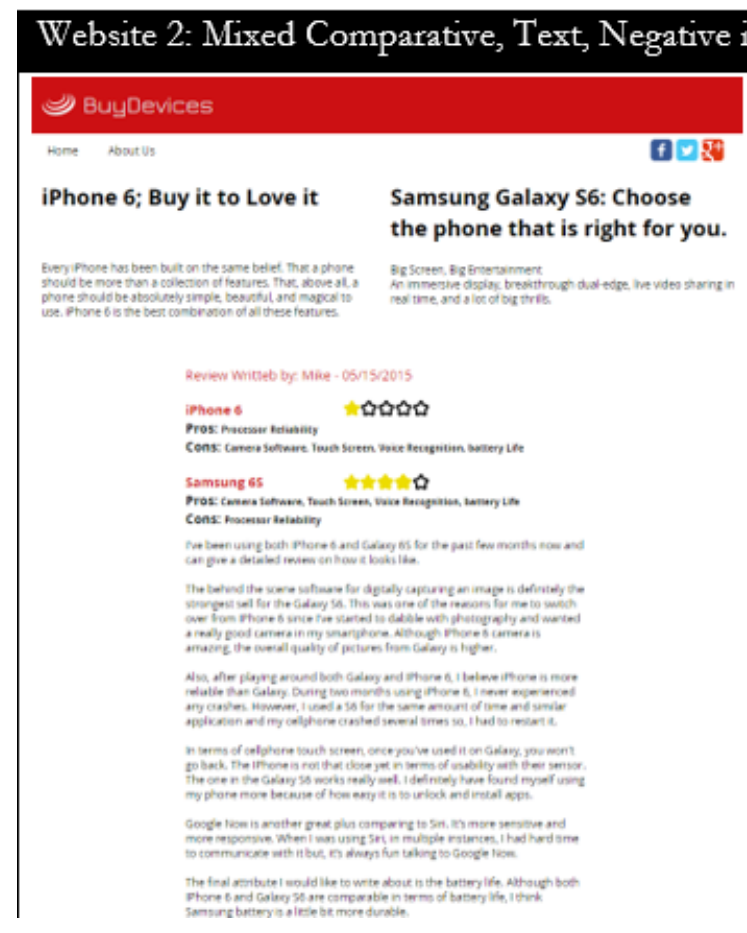

Figure 8.

\section{Website 3: Separate Comparative, Text, Positive iPhone, Negative Samsung}

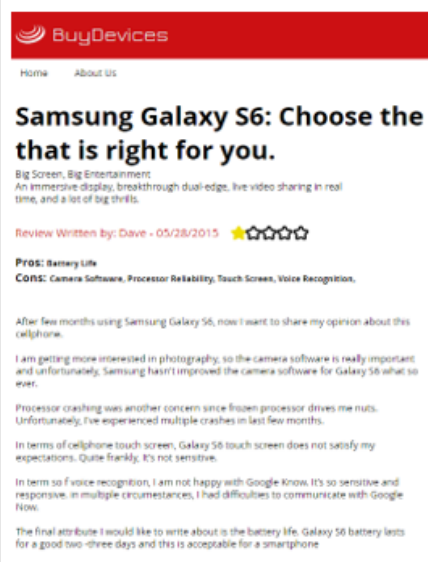

\section{iPhone 6; Buy it to Love it}

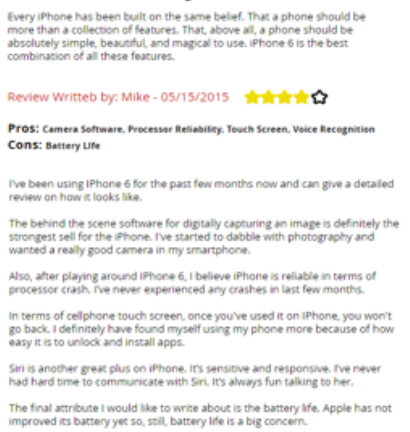


Journal of Global Information Management

Volume $29 \cdot$ Issue 6

Figure 9.

Website 4: Separate Comparative, Text, Negative iPhone, Positive Samsung

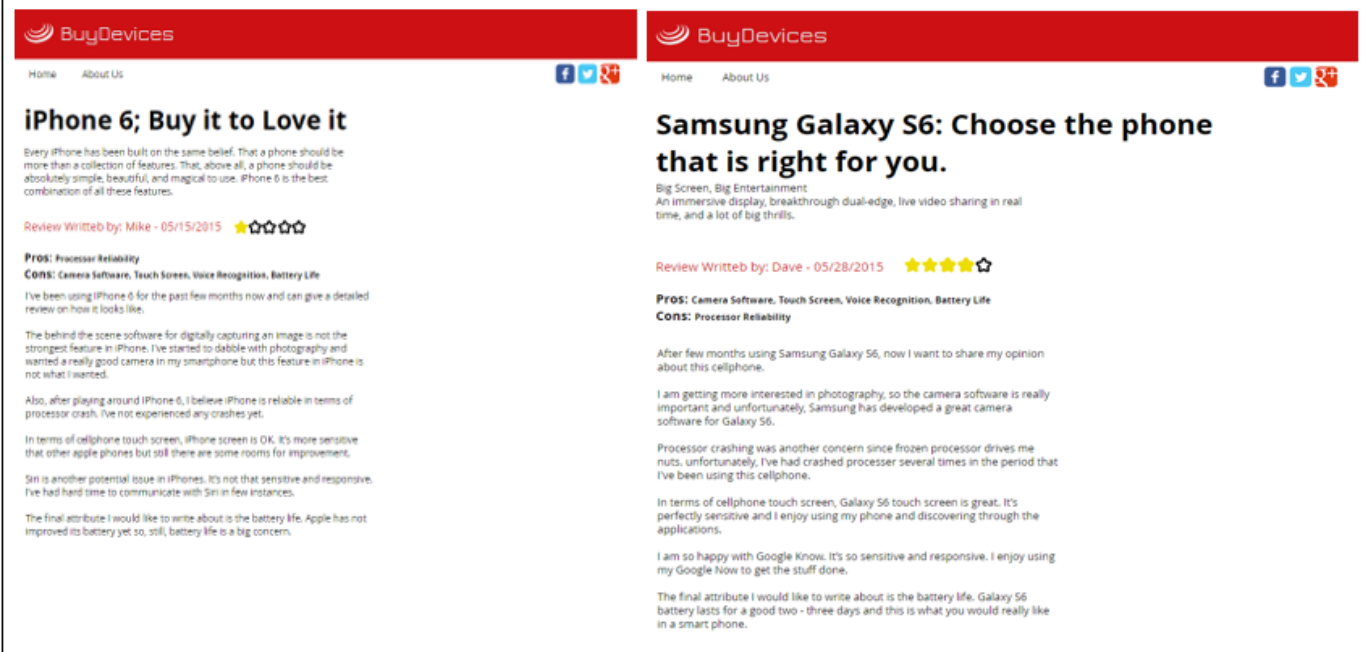

Figure 10.

Website 5: Regular Review about One Product, Text, Positive iPhone

()) BuyDevices

Home About U:

fogt

\section{iPhone 6; Buy it to Love it}

Every iphone has been built on the same belief. That a phone should be

more than a collection of features. That, above all, a phone should be

absolutely simple, beautiful, and magical to use. Fhone 6 is the best

combination of all these feacures.

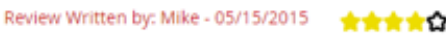

Pros: Comers Soltware, Processor Reliability, Touch Screen. Voike Recognition

Cons: Battery uife

Tve been using IPhone 6 for the past few monchs now and can give a decaled review on how it locks like.

The behind the scene software for digitally capturing an image is definitely the strongest sell for the iPhone. Ive started to dabble with photography and wanted a really good camera in my smartphone.

Also, atter playing around IPhone 6,1 believe Phone is reliable in terms of processor crash. Ne never experienced any crashes in last few months.

in terms of cellphone touch screen, once youve used it on IPhone, you wont go back. I definitely have found myself using my phone more because of how easy it is to unlock and install apps.

Siri is another grear plus on iphone. It's sensitive and responsive. Ive never

had hard time to communicate with Siri, it's always fun talking to her.

The final attribute I would like to write about is the battery life. Apple has

notimproved its battery yet, so still, battery lfe is a big concern. 
Figure 11.

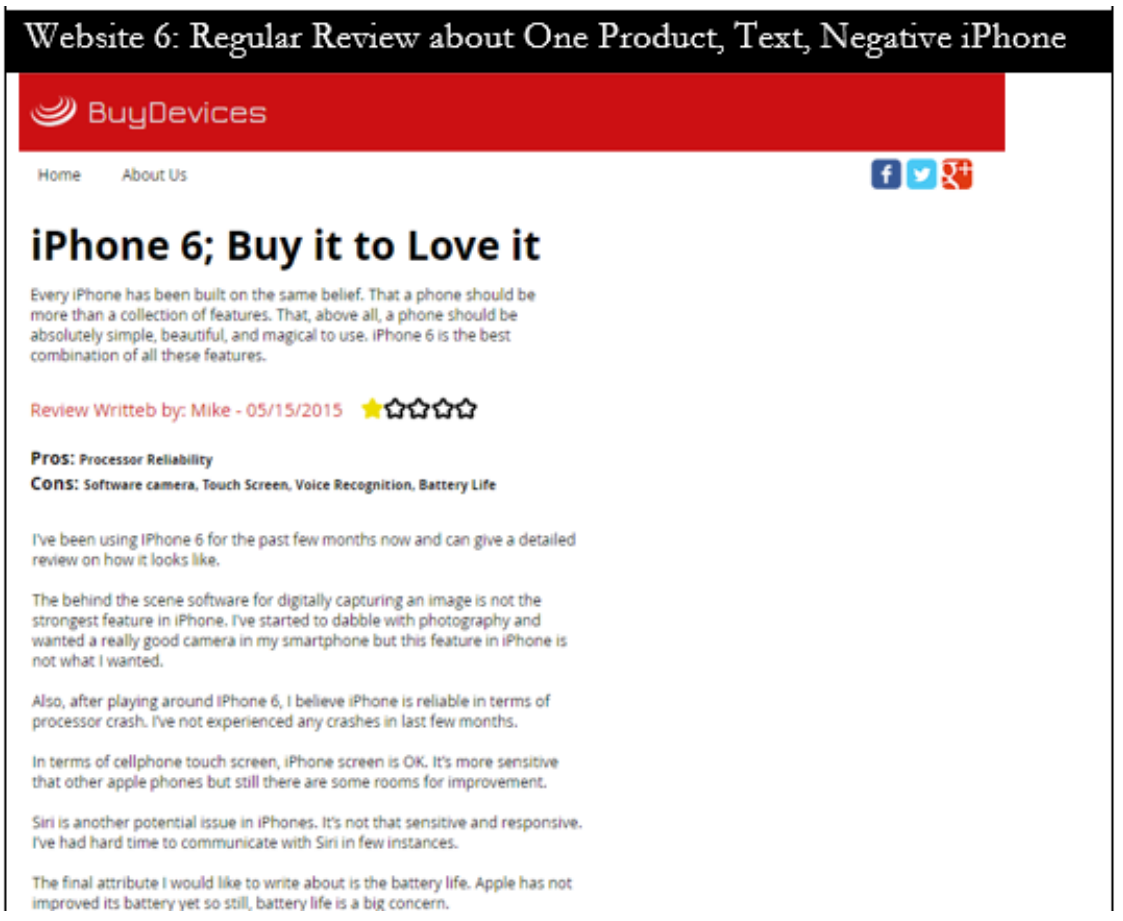

Figure 12.

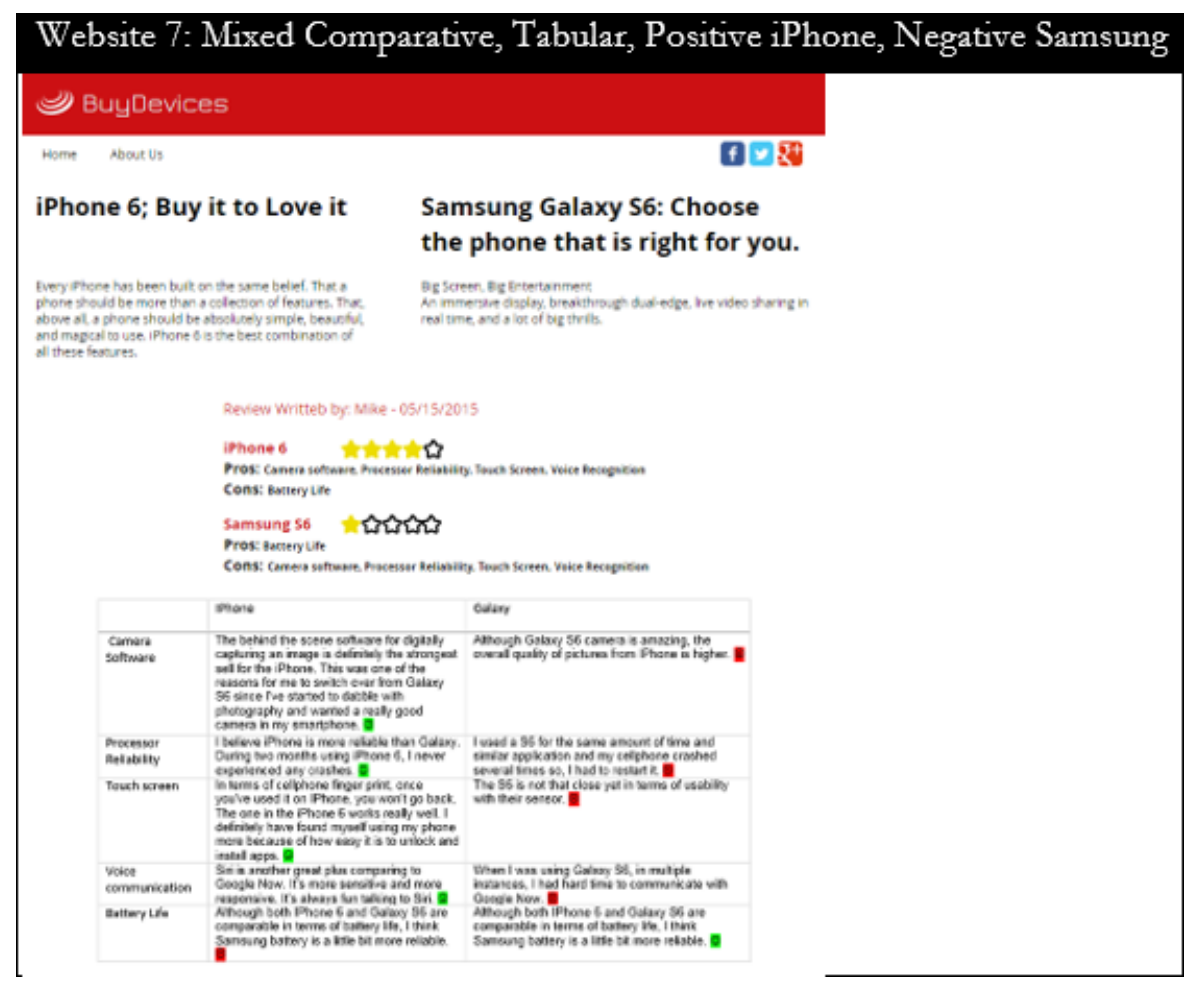


Figure 13.

\section{Website 8: Mixed Comparative, Tabular, Negative iPhone, Positive Samsung}

(Y) BuyDevices

Home Nboutus

iPhone 6; Buy it to Love it

\section{f 92}

Samsung Galaxy S6: Choose the phone that is right for you.

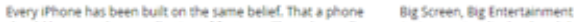

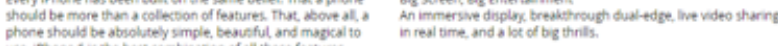
phone should be absolutely simple beaviful and magcal to

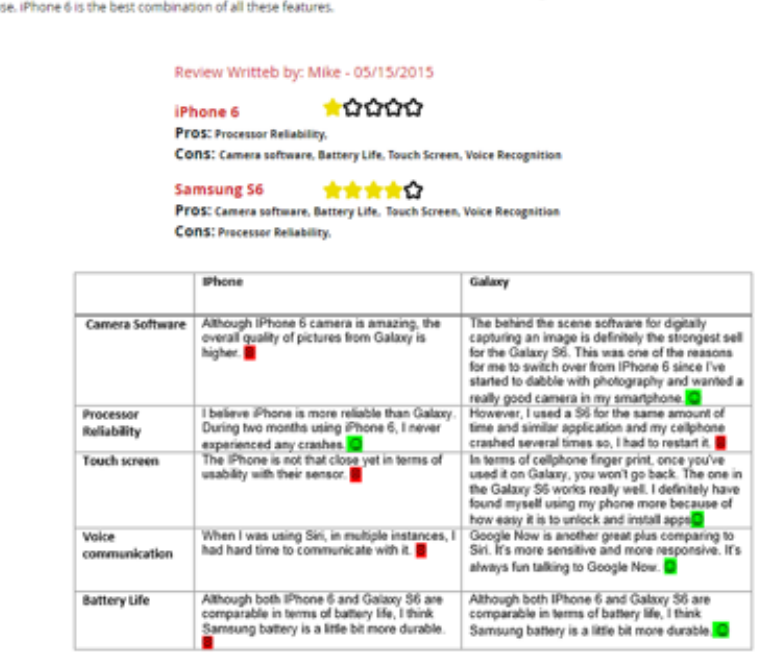

Figure 14.

\section{Website 9: Separate Comparative Review, Tabular, Positive iPhone, Negative Samsung}

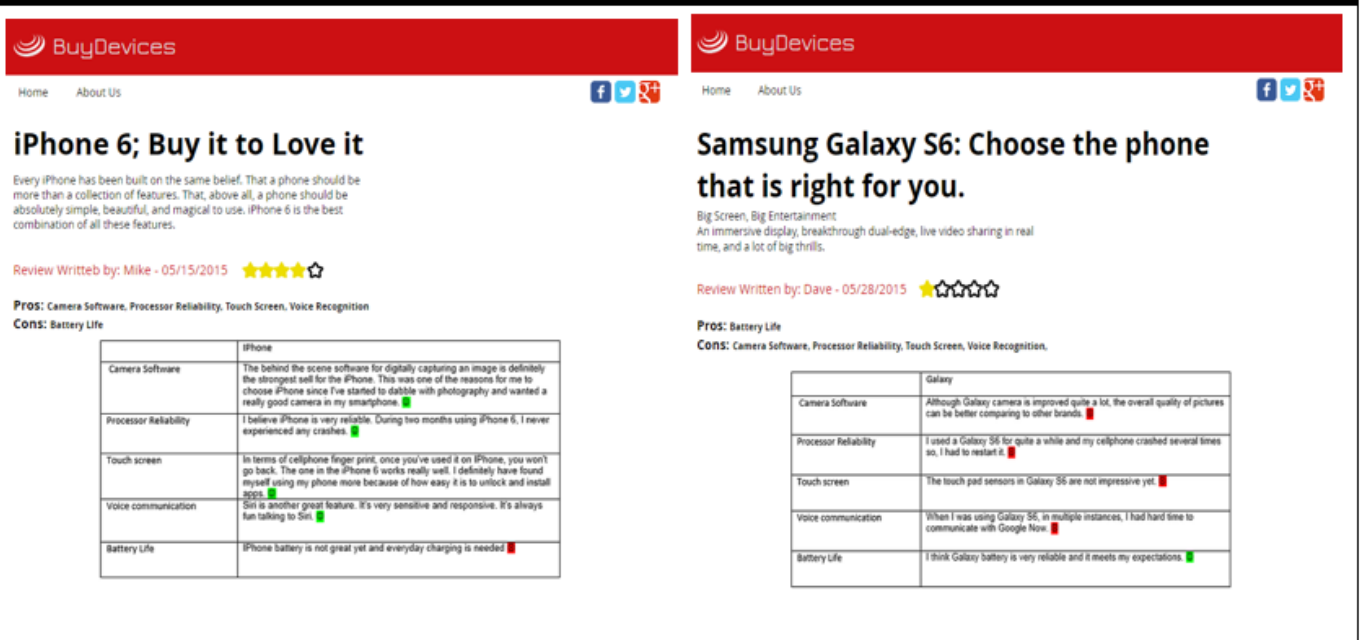


Figure 15.

Website 10: Separate Comparative Review, Tabular, Negative iPhone, Positive Samsung

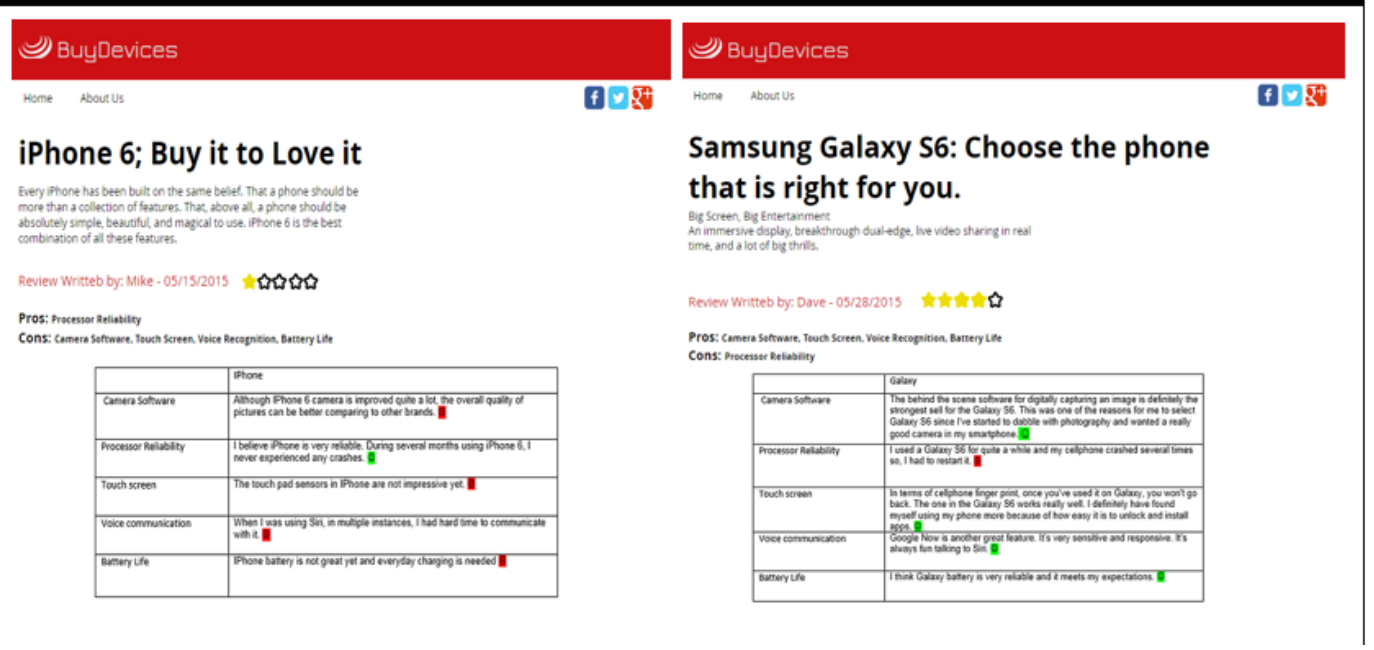

Figure 16.

\begin{tabular}{|c|c|c|}
\hline \multicolumn{3}{|c|}{$\begin{array}{l}\text { Website 11: Re } \\
\text { () BuyDevices }\end{array}$} \\
\hline \multirow{2}{*}{\multicolumn{3}{|c|}{ 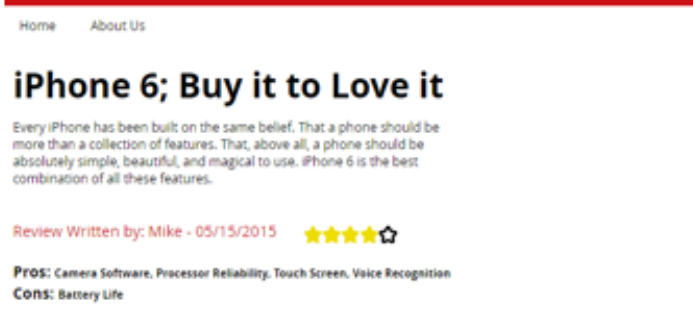 }} \\
\hline & & \\
\hline & & Howsen \\
\hline & Comera scthante & 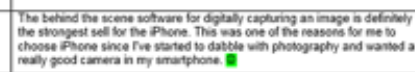 \\
\hline & 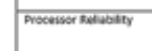 & 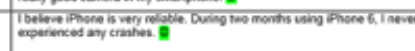 \\
\hline & Trouth souten & 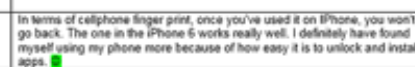 \\
\hline & Woke communication & 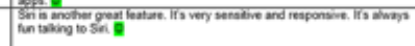 \\
\hline & Bamery the & 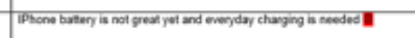 \\
\hline
\end{tabular}


Figure 17.

\section{Website 12: Regular Review about One Product, Tabular, Negative iPhone}

\section{(2) BuyDevices}

Home nooutvis

ดロझ

\section{iPhone 6; Buy it to Love it}

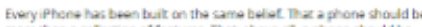

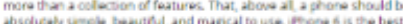

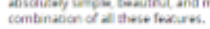

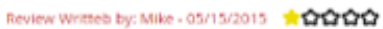

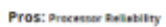

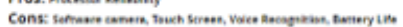

\begin{tabular}{|c|c|}
\hline & Frone \\
\hline caneres sohumer & 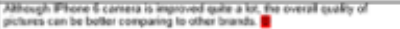 \\
\hline 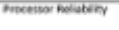 & 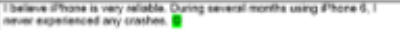 \\
\hline Touth screen & 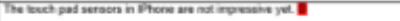 \\
\hline 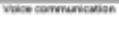 & 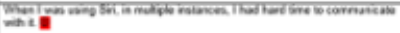 \\
\hline Betlention & 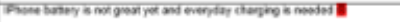 \\
\hline
\end{tabular}

\section{APPENDIX II.}

\section{Measures for Familiarity with Online Reviews and Product Knowledge}

\section{Table 11.}

\begin{tabular}{|l|l|}
\hline Variable & Measurement item \\
\hline $\begin{array}{l}\text { Familiarity with the } \\
\text { online review }\end{array}$ & $\begin{array}{l}\text { - When I buy a product online, I always read online reviews that are presented on web sites. } \\
\text { - When I buy a product online, the online reviews presented on web sites are helpful for my } \\
\text { decision making. } \\
\text { - When I buy a product online, reading the online reviews presented on web sites provides me } \\
\text { with benefits. }\end{array}$ \\
\hline Product knowledge & $\begin{array}{l}\text { - I am knowledgeable about cellphone attributes. } \\
\text { - Compared with experts, to what degree would you say that you have a good knowledge } \\
\text { about cellphones attributes? } \\
\text { - I am familiar with cellphone attributes. }\end{array}$ \\
\hline
\end{tabular}


Hessam Vali is the founder and senior operations consultant at Techam Solutions. He holds B.S, M.S. and PhD in industrial and manufacturing engineering as well as an MBA in finance. He is also a Six Sigma Black Belt with more than 15 years' experience in managing technical projects and driving the operations and processes optimization programs with strong track of operations KPI improvement and cost reduction. Hessam has a strong research background in field of marketing, customer behavior and experience. Hessam is also an affiliate faculty in department of Operations Management in Southwestern College teaching operations courses. He has papers published in International Conference on Information Systems, Americas' Conference on Information Systems, and Annual Industrial Engineering Conference.

Jingjun (David) $\mathrm{Xu}$ is an associate professor of Management Information Systems at City University of Hong Kong. He received his Ph.D. in MIS from the University of British Columbia. His research interests include HumanComputer Interaction, Social Media, E-Commerce, Computer-Mediated Deception, and Mobile Commerce. He has papers published in MIS Quarterly, Information Systems Research, Management Science, Journal of Management Information Systems, INFORMS Journal on Computing, Journal of the Association for Information Systems, Information Systems Journal, Journal of Strategic Information Systems, Journal of Business Ethics, among others. He received the AIS Early Career Award in 2018. He is the associate editor of Information Systems Research and Information Systems Journal.

Mehmet Bayram Yildirim is a professor in the Department of Industrial, Systems and Manufacturing Engineering at Wichita State University. He received a BS in industrial engineering from Bogazici University, Turkey in 1994; MS degree industrial engineering from Bilkent University, Turkey in 1996; and a PhD in industrial and systems engineering from the University of Florida in 2001. He has research interests in sustainability, supply chain management, energy aware production planning, generation expansion transmission planning, data enabled decision making and asset management. 